\title{
A APLICAÇÃO DO MÉTODO FMEA E SUAS IMPLICAÇÕES NO PLANEJAMENTO DE UMA MICROEMPRESA RURAL: ESTUDO DE CASO DA GRANJA OLIVEIRA
}

\section{THE METHOD FMEA AND ITS IMPLICATIONS IN PLANNING A RURAL MICRO- ENTERPRISE: A CASE STUDY OF FARM OLIVEIRA}

\author{
Caio César de Medeiros Costa* E-mail: caiocesq@hotmail.com \\ Leandro Gomes de Oliveira* E-mail: leandro.oliveira@ufv.br \\ Lydia Bruna da Costa Lima* E-mail: Iydia bruna@hotmail.com \\ Viviani Silva Lírio* E-mail: vslirio@ufv.br \\ *Universidade Federal de Viçosa, Viçosa, MG
}

\begin{abstract}
Resumo: A produção de frangos de corte, apesar do crescente espaço de mercado, ainda enfrenta importantes desafios na produção, tanto em nível básico quanto industrial. Nesse âmbito, este artigo resume as principais conclusões obtidas pela aplicação do método FMEA de hierarquização de falhas em uma granja de frango de corte, avaliando, também, as implicações sobre seu planejamento. Este estudo utilizou uma abordagem de estudo de caso, e a pesquisa, quanto aos objetivos, se caracteriza com descritiva. Os resultados mostraram que os problemas mais frequentes foram de caráter sanitário - frangos doentes e morte de frangos - tendo por origens principais falta de vacinação e excesso na capacidade de lotação da granja. Observou-se a adequação metodológica, pois o método FMEA contribuiu, entre outros pontos, para a resolução dos chamados problemas estruturados, uma vez que, pela implantação do método, foi possível conhecer melhor os possíveis erros e falhas que, por ventura, possam vir a ocasionar esses problemas, dando ao gestor segurança no tratamento dessas questões e possibilitando a realização de um planejamento. Espera-se, com esta pesquisa, contribuir para o aprimoramento da gestão de granjas de frango de corte e, de forma indireta, apoiar a melhoria da rentabilidade dos avicultores pela sua conscientização acerca da importância da aplicação de ferramentas de gestão da qualidade.
\end{abstract}

Palavras-chave:Gestão da qualidade. Planejamento. Mmicroempresa rural. Frango de corte e falhas.

Abstract: The production of broiler chickens, in despite of the growing market space, it still faces important challenges in production, at basic and industrial level at the same time. In this context, this article summarizes the main conclusions of the application of FMEA in a broiler farm, analyzing also the implications for their planning. This study used descriptive and a case study approach. The results showed that the most frequent problems were characterized, for example as sick chickens and chicken deaths - with the main sources of vaccine shortage and excess in the carrying capacity of the farm. It was observed that the method FMEA was appropriate and contributed for the analyzes, for instance, to the resolution of the structured problems, since, by implementing the method, we could better understand the possible errors and failures that, perhaps, probably can cause these problems, giving the manager security issues and enabling the execution of a plan. So, this research brings the expectative to improve the management of broiler farms and, indirectly, can aid the profitability of poultry farmers, for their awareness of the importance of use quality management tools.

Key-words: Quality management. Planning. Rural micro enterprise. Broiler and failures. 


\section{INTRODUÇÃO}

A carne de frango, cada vez mais presente nas refeições dos brasileiros, apresentou nos últimos anos uma grande expansão em sua produção. Aos olhos dos consumidores, gradativamente deixou de ser uma carne nobre, destinada exclusivamente às classes econômicas de maior renda, para estar hoje difundida em todos os níveis socioeconômicos do País. Essa evolução, que de certa maneira pode estar relacionada à evolução da renda média nacional, se baseia, principalmente, no desenvolvimento tecnológico e mercadológico da cadeia produtiva da carne de frango. Outro fator que contribuiu para o desempenho da produção desses itens é o resultado do comercio exterior brasileiro, sendo o Brasil, atualmente, o maior exportador mundial de carne de frango (MARTINS et al., 2006).

De acordo com dados da Associação Brasileira dos Exportadores de Frango, Abef (2011), o Brasil no ano de 2010 foi o maior exportador de carne de frango do mundo, com mais de 3,819 milhões de toneladas, trazendo para o País US $\$ 6,808$ bilhões em receitas cambiais. A produção de carne de frango chegou a 12,230 milhões de toneladas em 2010 , crescimento de $11,38 \%$ em relação a 2009 , quando foram produzidas 10,980 milhões de toneladas.

De uma atividade voltada para subsistência até o início da década de 1970, a avicultura nacional modernizou-se significativamente nos 30 anos subsequentes. Paralelamente, o consumo per capita de carne de frango cresceu, principalmente, a partir dos anos de 1980, indicando maiores possibilidades de expansão para essa atividade, tanto interna quanto externamente. Dentro deste contexto, em que se chama atenção para o dinamismo da avicultura empresarial nacional, a produção da avicultura brasileira expandiu-se substancialmente, com crescentes ganhos de produtividade, além da obtenção de um produto de excelente qualidade (MARTINS et al., 2006).

Esse conjunto de fatores indica a cadeia do frango de corte no Brasil como uma das mais bem organizadas, sendo um modelo de competitividade. Pela sua estrutura e relevância, tem grande importância no cenário nacional pelo alto consumo interno, que, no ano de 2010, segundo dados da Abef (2011), foi de 44 quilos per capita. A cadeia do frango é, ainda, grande geradora de empregos em 
todos os elos e a maioria dos produtores trabalha de forma integrada com os abatedouros e agroindústrias.

$\mathrm{Na}$ integração entre agroindústrias e produtores, as primeiras entregam as matrizes aos produtores que desenvolvem o processo de cria e engorda dos frangos. O produtor é remunerado conforme uma conversão de ganho de peso estipulada pela agroindústria. Nesta conversão, quanto mais elevada, maior será a rentabilidade do produtor. Por isso, a importância da aplicação das ferramentas de gestão da qualidade em nível do produtor, objetivando maior lucro e recebimento pela agroindústria de um produto com melhor qualidade.

Hoje, a avicultura integrada foi consolidada inclusive com os pequenos produtores. No estado de Minas Gerais, ela se baseia na utilização de mão de obra familiar, pequenas extensões de terra e propriedades diversificadas. $O$ ingresso das empresas no sistema de integração foi motivado pela tendência de mercado, buscando garantir homogeneidade da matéria-prima e suprimento da capacidade de abate. Como resultado, as agroindústrias obtiveram redução da necessidade de investimento, diminuição das despesas operacionais e aumento da produtividade (RICHETTI e SANTOS, 2000). Verifica-se a importância dos pequenos produtores para a cadeia como um todo no sentido de garantir homogeneidade da matériaprima e suprimento da capacidade de abate, características cruciais para que a cadeia seja competitiva.

É importante considerar, adicionalmente, que, com 0 aumento da competitividade, houve um aumento das exigências do consumidor e uma maior organização da cadeia. Outro motivo muito importante para a aplicação de ferramentas de gestão da qualidade é a segurança alimentar, que deverá conduzida segundo o relatório "Assegurando a Segurança dos Alimentos: da Produção ao Consumo", de 1998, a pedido do congresso americano. A cada ano são identificadas cerca de 9.000 mortes e 81 milhões de doenças, atribuídas à ingestão de alimentos contaminados ( ROONEY, 2002).

Nesse escopo, umas das ferramentas possíveis de ser utilizada no elo da produção da cadeia do frango é a "Análise dos Modos e Efeitos de Falhas" (FMEA), uma técnica que identifica falhas e problemas ou erros do processo antes que ele chegue ao usuário. O FMEA é um método usado para identificar todos os possíveis 
modos de falha e determinar o efeito de cada uma sobre o desempenho do sistema (produto ou processo), mediante um raciocínio basicamente dedutivo (CONTE e CAMPANI, 2007).

Nesse contexto o presente trabalho teve como objetivo estudar a aplicação do FMEA em uma granja de frango que se encontra integrada, avaliando, também, os impactos desse método no planejamento desta granja.

Este artigo está organizado da seguinte forma: depois desta introdução, é apresentado o referencial teórico composto das seções gestão da qualidade no agronegócio e planejamento da microempresa rural. A seção 3 mostra os procedimentos metodológicos que subsidiaram as análises. A seção 4 , os resultados e suas discussões, e a seção 5 , as considerações finais.

\section{REFERENCIAL TEÓRICO}

\subsection{Gestão da Qualidade no Agronegócio}

A implementação do conceito moderno de Gestão da Qualidade teve sua origem no Japão, tendo como referência teórica o trabalho e o acompanhamento de cientistas americanos. A base teórica e histórica da Gestão da Qualidade é constituída por diversos trabalhos (DEMING, 1982; JURAN, 1990; FEIGENBAUM, 1986; ISHIKAWA, 1985; CROSBY 1988).

A Gestão da Qualidade tem o objetivo de reduzir o número de falhas na produção, visando, como meta, ao nível zero de erros. Não deve haver produtos sem qualidade, ou seja, produtos que não atendam às expectativas e exigências do consumidor (SILVA JR, 2003).

Buscando uma redução nos níveis de tolerância ao erro, as empresas buscam a criação de sistema de gestão da qualidade, a gestão da qualidade total. Entre as várias definições de qualidade, Deming (1982) aponta que a qualidade seria representada pela melhoria contínua de produtos e processos, visando à satisfação dos clientes. Por sua vez, Crosby (1992) define a qualidade como a conformidade com os requerimentos dos clientes. 
Outras abordagens acerca da qualidade são constantes na literatura. Garvin (1988) aponta a existência de cinco abordagens principais: a transcendental, a baseada no produto, a baseada no usuário, a baseada na produção e, por fim, a baseada no valor.

Ainda de acordo com Garvin (1988), a abordagem transcendental define a qualidade como sinônima de excelência inata, sendo absoluta e universalmente reconhecida; em contraponto, a abordagem baseada no produto aponta a qualidade como uma variável precisa e mensurável, oriunda dos atributos do produto.

A abordagem baseada no usuário difere das anteriores apontando a qualidade como uma variável subjetiva, e que produtos de melhor qualidade são aqueles que atendem melhor aos desejos dos consumidores. Outra abordagem, a baseada na produção, assim com a baseada no produto, diz que a qualidade é precisa e mensurável, porém ela é oriunda do grau de conformidade do planejado com o executado. Por fim, a abordagem baseada no valor afirma, segundo Broh (1974), que a qualidade é o grau de excelência a um preço aceitável.

O tema da gestão da qualidade total apresenta diversas definições. Vieira $(1996,1999)$ identifica seis características comuns à maioria das práticas relativas à qualidade nas organizações: 1) integração dos membros da organização por meio de um ambiente participativo; 2) criação de comprometimento e entusiasmo pela qualidade desde os níveis mais altos da hierarquia até o chão de fábrica; 3) comprometimento com o melhoramento contínuo; 4) conjunto de técnicas, especialmente aquelas relacionadas a sistemas flexíveis de manufatura; 5) desejo e disposição para fazer um investimento substancial em treinamento como parte de uma política de recursos humanos; e 6) transcendência de fronteiras departamentais e disciplinares e uso de técnicas de solução de problemas em grupo e de trabalhos em equipes, num ambiente de relações de alta confiança.

Dessa forma, a adoção de diferentes práticas que permeiam a questão da qualidade nas organizações deve ser realizada pelos mais diferentes setores da economia e pelas mais distintas organizações, desde as empresas baseadas na agricultura familiar até as grandes multinacionais.

Diversos são os métodos que visam a garantir a qualidade na produção de bens e serviços, destacando-se entre eles o FMEA. Segundo Ooakalkar, Joshi e 
Ooakalkar (2009), o FMEA é uma análise em perspectiva qualitativa que ajuda a identificar e resolver os pontos fracos e vulneráveis em um produto e ou processo. Entre as vantagens e uma das principais causas de grande utilização do método está a não padronização dos formulários, o que possibilita que cada empresa promova a implantação de acordo com as suas características.

Em algumas cadeias de produção, que exigem um maior nível de qualidade, a documentação do FMEA é um requisito para a obtenção de selos de qualidade. A produção de veículos nos EUA e em outros países utiliza o FMEA como parte na obtenção do sistema de qualidade, o ISO - 9000 (TENG et al., 2006).

Os fabricantes de equipamentos originais automotivos utilizam o FMEA no processo de design para projetos de maior parte e exigem que seus fornecedores apresentem o FMEA como parte da documentação do produto para sua aprovação (AIAG, 1995; SAE, 2002).

A exigência da implantação de métodos que visam a garantir a qualidade dos produtos é de grande relevância em praticamente todas as cadeias produtivas, e um grande número de agentes dificulta ainda mais a garantia de qualidade do produto sendo necessária a implementação de praticas dessa natureza em todos os elos. Nesse sentido, para produtos cuja matéria-prima é de origem animal ou vegetal do setor do agronegócio, a preocupação com a qualidade deve ser ainda maior haja vista que algumas falhas podem ser cruciais podendo inclusive causar danos à saúde do consumidor.

Levando-se em conta a definição de agronegócio apresentada por Davis e Goldberg (1957) como "a soma das operações de produção e distribuição de suprimentos agrícolas, do armazenamento, processo e distribuição dos produtos agrícolas e itens produzidos a partir deles", verifica-se a necessidade de a gestão da qualidade abarcar todos os elos da cadeia produtiva, desde o grande produtor de insumos, passando pela pequena propriedade rural, até chegar aos grandes distribuidores.

Entre os aspectos que influenciam as empresas na busca pela excelência em termos de qualidade, o consumidor se apresenta como protagonista, e, segundo Zylbersztajn (2003), ele, que antes era um agente passivo, passa a ser atuante nas 
cadeias produtivas, sinalizando toda ela com respeito a seus desejos quanto a informações e à qualidade dos produtos que consome.

Tendo como base as considerações trazidas anteriormente, é possível afirmar que a questão da qualidade é bastante ampla, indo além da simples padronização dos produtos. E em se tratando de produtos do setor alimentício, essa questão deve ser tratada ainda com mais atenção, haja vista o risco iminente para a saúde dos consumidores, caso o produto chegue a eles sem a devida qualidade.

\subsection{Planejamento da microempresa rural}

O modelo de gestão rural familiar adotado pela grande maioria das empresas rurais de base familiar suscita preocupações por diferentes motivos. Entre eles se destacam o estilo de administração, a falta de controles de custos de produção, a carência da inserção da tecnologia da informação, a agilidade na tomada de decisões diante de situações complexas e, especialmente, a falta de planejamento estratégico (PADILHA et al., 2010).

Segundo Vilckas (2004), a elaboração e a implementação do planejamento no setor rural representam um desafio muito grande, tendo em vista que os empreendimentos desse setor estão sujeitos a um grande número de variáveis, como a dependência de recursos naturais, a sazonalidade de mercado, a perecibilidade dos produtos, o ciclo biológico de vegetais e de animais e o tempo de maturação dos produtos.

Estudos da Confederação da Agricultura e Pecuária do Brasil, citados por Oliszeski e Colmenero (2010), mostram que a utilização de ferramentas gerenciais pelos produtores ainda é bastante reduzida, porém os produtores têm percebido que apenas conhecimentos técnicos acerca dos processos de produção/criação, embora fundamentais, não bastam, reconhecendo-se a importância da administração, em especial a do planejamento, em suas atividades.

O entendimento acerca da necessidade de planejar e implantar ferramentas gerenciais no âmbito das propriedades rurais familiares tem sido cada vez mais difundido. Esse entendimento se dá em especial pela exigência dos demais agentes da cadeia em garantir um produto de qualidade e fugir das incertezas do mercado, 
as quais impactam de uma forma mais enfática as empresas cuja prática de ferramentas de gerenciais ainda não foi incorporada às suas rotinas.

O planejamento, tomando como base Scarpelli (2007), é uma atividade que trata problemas não estruturados, de longo prazo, que dão margem às grandes decisões da empresa. São considerados problemas não estruturados aqueles que não admitem uma forma sistemática de tratamento pelo ineditismo das situações e variáveis, exigindo uma alta dose de subjetivismo e experiência em sua resolução.

O planejamento envolve significativos volumes de informação e processamento, demanda tempo de desenvolvimento, de projeto e de execução, e por ser sistemático, ele exige monitoramento e avaliação das condições concorrenciais e tecnológicas, bem como significativos aportes financeiros (SCARPELLI, 2007). Devido a esses e outros fatores é que o planejamento se destaca como uma das mais importantes ferramentas gerenciais.

No que tange a empresas rurais de base familiar, a dificuldade de implementar ferramentas gerenciais (entre elas o planejamento) é ainda maior, devido, entre outros aspectos, ao fato de as práticas utilizadas terem sido passadas de pai pra filho, o que dificulta o rompimento dessas práticas reiteradas presentes nas rotinas da empresa.

O planejamento, segundo Chiavenato (2003), deve maximizar os resultados e minimizar as deficiências da empresa. Por sua vez, Oliveira (2004) aponta que o planejamento não é um ato isolado, devendo ser encarado como um processo de ações inter-relacionadas e interdependentes que visam ao alcance de objetivos previamente estabelecidos. Tomando como base esses conceitos, pode-se afirmar que o planejamento visa a definir padrões, resultados e ações que devem ser alcançados e realizados ao longo de toda a produção de um determinado bem.

Percebe-se assim a importância da implantação de ferramentas de gestão da qualidade nas empresas rurais, visto que, por meio delas é possível a adoção de práticas de gestão nessas empresas, haja vista o fato de algumas dessas ferramentas - entre elas o método FMEA - deixar claro ao produtor todas as consequência oriundas daquelas falhas que poderiam ter sido evitadas pela simples adoção de práticas de gestão como o planejamento. 


\section{METODOLOGIA}

\subsection{Delineamento da pesquisa}

Este trabalho empregou uma abordagem de estudo de caso que, de acordo com Yin (1981), é um estudo empírico que investiga um fenômeno atual dentro do seu contexto de realidade, quando a fronteira entre o fenômeno e o contexto não é claramente definida, sendo utilizadas várias fontes de evidências. A utilização dessa abordagem vem sendo cada vez mais adotada pelos pesquisadores das ciências sociais.

Quanto aos objetivos, trata-se de uma pesquisa descritiva que visa a descrever a aplicação do método FMEA em uma granja de frango e, por consequência, conhecer suas implicações no planejamento da empresa rural estudada. Segundo Solomon (2004), a pesquisa descritiva é aquela que visa a definir melhor o problema, proporcionar as chamadas intuições de solução, descrever comportamentos e fenômenos, definir e classificar fatos e variáveis.

A coleta de dados que possibilitaram a definição dos índices foi realizada na sede da Granja Oliveira, zona rural de Ubá/MG. Foram entrevistados para esse estudo todos os membros do grupo familiar, no caso em questão, seis membros, os quais compõem a totalidade da mão de obra dessa empresa rural baseada na mão de obra familiar. As entrevistas ocorreram entre os dias 14 e 15 de maio de 2010.

Optou-se pela escolha dessa empresa pela facilidade na obtenção dos dados e também pelo fato de a grande maioria das granjas instaladas no estado possuírem características muito similares à granja estudada.

\subsection{Aplicação do Método "Análise dos Modos e Efeitos de Falhas" - FMEA}

A FMEA, muito utilizado pelas grandes empresas, tem sido mais recentemente aplicada também a médias e pequenas empresas para identificar as falhas, sejam elas de produto ou de processo.

Apesar de terem sido conduzidas análises semelhantes, de forma desestruturada, a primeira aplicação formal da FMEA foi uma inovação da indústria 
aeroespacial em meados dos anos 60 (MOURA, 2000). Stamatis (1995) define o FMEA como um método de análise de produtos ou processos usado para identificar todos os possíveis modos potenciais de falha e determinar o efeito de cada um desses modos sobre o desempenho do sistema, mediante um raciocínio basicamente dedutivo (não exige cálculos sofisticados). É, portanto, um método analítico padronizado para detectar e eliminar problemas potenciais de forma sistemática e completa.

De acordo com Silva Jr. (2003), o objetivo da Análise dos Modos e Efeitos das Causas é detectar possíveis erros, avaliá-los e evitá-los, mediante ações adequadas. Apesar de ter sido desenvolvida com um enfoque no projeto de novos produtos e processos, a metodologia FMEA, pela sua grande utilidade, passou a ser aplicada de diversas maneiras. Assim, ela atualmente é utilizada para diminuir as falhas de produtos e processos existentes e para diminuir a probabilidade de falha em processos administrativos. Tem sido empregada também em aplicações específicas como análises de fontes de risco em engenharia de segurança e na indústria de alimentos (TOLEDO e AMARAL, 2000).

Idealmente, o FMEA deve ser uma ação "antes do evento", e não um exercício "após o fato". Para obter melhores resultados, a FMEA deve ser feita antes de um modo de falha ter sido incorporado ao produto sem ter sido percebido (MOURA, 2000)

O método FMEA foi desenvolvido pela NASA, em meados dos anos 1960, e sua aplicação principal ocorre na análise de processos e segue cinco fases (PFEIFER, 1994):

1) Organização (definir equipes e cronograma);

2) Preparo do conteúdo (determinar etapas do processo produtivo a ser analisado);

3) Análise propriamente dita;

4) Interpretação dos resultados; e

5) Avaliação da eficiência das ações corretivas implantadas. 
De acordo com Morreti e Bigatto (2004), todas as informações e dados levantados são então reunidos em um documento, na forma de uma tabela, que permite a rápida compreensão e avaliação dos resultados obtidos. Segundo Silva Jr. (2003), na tabela do método FMEA constam dez colunas: na primeira coluna, determina-se qual etapa do processo será analisada; na segunda coluna, cada possível erro que possa ocorrer na etapa é determinado; já na coluna 3 , são apresentadas as possíveis causas do erro; e na quarta coluna, quais as consequências do erro.

Em sequência, passa-se à fase de determinação do risco (coluna 9), que é o produto da probabilidade de ocorrência(6), seriedade do efeito do erro (7) e dificuldade em detectar a irregularidade (8). Esta análise é dificultada pela falta de dados e de sua padronização. Ações preventivas e corretivas são descritas na coluna (10) (SILVA JR, 2003).

Existem duas formas de analisar os resultados obtidos. A primeira delas, tradicional, é feita através do número de prioridade de risco (NPR). Na segunda, mais visual e preventiva, constrói-se um gráfico em que num eixo indica-se a possibilidade de ocorrência de um dado modo de falha ou suas causas e no outro, a sua severidade (impacto da falha sobre ao cliente) (MORRETI e BIGATTO, 2004).

O cálculo do número de prioridade do risco (NPR) é feito multiplicando entre si os valores atribuídos à probabilidade de ocorrência $(P)$, à seriedade do risco(S) e à dificuldade de detecção(D), sendo dado pela equação (1):

$$
N P R=P x D x S
$$

Para cada um das variáveis envolvidas no cálculo do número de prioridade do risco são atribuídos valores constantes num intervalo de 0 a 10. De acordo com Toledo e Amaral (2000), os critérios para determinar o risco são dados pelas Tabelas e Quadros de 1 a 3.

A tabela 1 apresenta os critérios para a definição dos índices de severidade 
Tabela 1 - Critérios de seleção de índices de severidade.

\begin{tabular}{ccc}
\hline Índice & Seriedade & Critério \\
\hline 1 & Mínima & O cliente mal percebe que a falha ocorreu \\
\hline 2 & Pequena & $\begin{array}{r}\text { Ligeira deterioração no desempenho com leve } \\
\text { descontentamento do cliente }\end{array}$ \\
4 & Moderada & $\begin{array}{c}\text { Deterioração significativa no desempenho de um } \\
\text { sistema com descontentamento do cliente }\end{array}$ \\
6 & Alta & $\begin{array}{c}\text { Sistema deixa de funcionar e grande } \\
\text { descontentamento do cliente }\end{array}$ \\
7 & Muito Alta & Idem anterior, porém afetando a segurança \\
\hline 9 & &
\end{tabular}

Na Tabela 2, são apresentados os critérios que, de acordo com Toledo e Amaral (2000), devem ser utilizados para definir qual índice atribuir à ocorrência do erro.

Tabela 2 - Critérios de definição de índices de probabilidade de ocorrência

\begin{tabular}{ccc}
\hline Ocorrência & Índice & Proporção \\
\hline Remota & 1 & $1: 100.000$ \\
Pequena & 2 & $1: 20.000$ \\
& 3 & $1: 4.000$ \\
Moderada & 4 & $1: 1.000$ \\
& 5 & $1: 400$ \\
Alta & 6 & $1: 80$ \\
& 7 & $01: 40$ \\
Muito Alta & 8 & $01: 20$ \\
& 9 & $01: 08$ \\
\hline
\end{tabular}

Fonte: Toledo e Amaral (2000).

Na Tabela 3, são apresentados os critérios, que segundo Toledo e Amaral (2000), são utilizados para definição dos índices de dificuldade de detecção. 
Tabela 3 - Critérios para definição de índices de dificuldade de detecção

\begin{tabular}{ccc}
\hline Índice & Detecção & Critério \\
\hline 1 & Muito Grande & Certamente será detectado \\
2 & & \\
3 & Grande & Grande probabilidade de ser detectado \\
4 & & Provavelmente será detectada \\
5 & Moderada & \\
6 & & Provavelmente não será detectada \\
8 & Pequena & \\
9 & & Certamente não será detectado \\
10 & Muito pequena &
\end{tabular}

Fonte: Toledo e Amaral (2000)

Utilizando esses critérios para definição dos índices, calcula-se o risco para cada erro, sendo que aqueles em que o índice de probabilidade de ocorrência for maior ou igual a 5 devem ser tratados com maior atenção; os demais, cujo o número de prioridade do risco (NPR) for maior ou igual a 300, também devem ser trabalhados com maior atenção (SILVA Jr., 2003).

\section{RESULTADOS E DISCUSSÃO}

\subsection{Caracterização da empresa}

Esta pesquisa teve como objeto de estudo uma granja de corte representativa na Zona da Mata Mineira. Encontra-se localizada na cidade de Ubá - MG,possui 1,7 alqueire de área e é a única fonte de renda da propriedade, sendo os trabalhos executados com mão de obra exclusivamente familiar.

O proprietário construiu o galpão em 1994, seguindo as normas da Associação dos Avicultores da Zona da Mata Mineira (Avizon). O galpão tem 100 metros de comprimento por 12 metros de largura, podendo acomodar até 14.000 frangos por lote ${ }^{1}$. A proximidade do galpão com a agroindústria Pif-Paf, sete

\footnotetext{
${ }^{1}$ Lote é o período em que os pintinhos permanecem na granja para engorda até serem abatidos na agroindústria. Esse tempo varia muito, mais gira em torno de 45 dias.
}

Revista Produção Online. Florianópolis, SC, v.11, n. 3, p. 757-778, jul./set., 2011. 
quilômetros, possibilita o atendimento rápido caso ocorra algum tipo de problema no decorrer da criação, contando a agroindústria com zootecnistas e veterinários para dar esse suporte ao avicultor. A essa parceria entre de agroindústria e avicultor dáse o nome de integração.

\subsection{Aplicação do Método FMEA}

$\mathrm{Na}$ aplicação do método selecionado, foram definidas quatro funções, consideradas pelo proprietário como as mais importantes do processo pelo qual o frango passa na granja, antes de ser levado ao abate. São elas: limpeza do galpão, crescimento dos frangos, engorda do frango e chegada do frango. Os dados relacionados no Quadro 1 apresentam as funções, modo de falha e o efeito que cada uma destas funções causa no processo e no produto final

Quadro 1 - Funções, modos de falha e efeitos

\begin{tabular}{|c|c|c|}
\hline Função & Modo de Falha & Efeito \\
\hline Limpeza do Galpão & Limpeza inadequada & $\begin{array}{l}\text { Possibilidade de contaminação, levando } \\
\text { a prejuízos financeiros, prejudicando a } \\
\text { imagem da empresa. }\end{array}$ \\
\hline Crescimento do Frango & Morte de Frangos & $\begin{array}{l}\text { A morte de frangos antes do abate é } \\
\text { muito prejudicial à empresa, pois além } \\
\text { do custo atrapalha o planejamento e } \\
\text { pode levar à falta do produto. }\end{array}$ \\
\hline Engorda do Frango & Frango Doente & $\begin{array}{l}\text { Um possível dano à saúde do } \\
\text { consumidor pode ser muito danoso à } \\
\text { imagem da agroindústria avícola, } \\
\text { causando, além disso, grandes perdas } \\
\text { como pagamentos de multas e de } \\
\text { indenizações. }\end{array}$ \\
\hline Engorda do Frango & Frango não ganha peso & $\begin{array}{l}\text { Com os frangos abaixo do peso, } \\
\text { diminui a produção final em termos de } \\
\text { quilos e, além disso, traz perdas por } \\
\text { falta de padronização e insatisfação do } \\
\text { cliente. }\end{array}$ \\
\hline Chegada do Frango & Frango com aspecto ruim & $\begin{array}{l}\text { Os danos maiores são de imagem, pois } \\
\text { segundo pesquisas o aspecto é um dos } \\
\text { fatores com que os clientes mais se } \\
\text { preocupam. }\end{array}$ \\
\hline
\end{tabular}

Fonte: Resultados da pesquisa - Elaborada pelos autores. 
Após a definição das principais etapas/identificação de erros, foi elaborada a plotagem do método FMEA (Tabela 4). Nele, a coluna controle foi excluída de modo a facilitar a visualização das informações; além disso, o controle realizado, devido à falta de tecnologia e de recursos das granjas, é apenas via inspeção visual. Observou-se que alguns erros são motivados por causas comuns e deveriam ser monitorados de forma mais ativa.

Os efeitos, as causas e as ações propostas visando à correção das falhas foram baseadas na literatura especializada sobre criação de frango de corte, destacando-se entre eles Ivey (1999), Araújo et al.(2002), Stringhin et al(2003) e Moreira et al. (2004). 
Tabela 4 - Aplicação do Método FMEA na granja Oliveira

\begin{tabular}{|c|c|c|c|c|c|c|c|}
\hline $\begin{array}{l}\text { Modo de } \\
\text { Falha }\end{array}$ & Causa & (P) & (D) & (S) & Efeito & $\begin{array}{c}\text { Risco } \\
(\text { PxDxS) }\end{array}$ & Ações \\
\hline \multirow{4}{*}{$\begin{array}{l}\text { Frango } \\
\text { Doente }\end{array}$} & $\begin{array}{l}\text { Ambiente } \\
\text { barulhento }\end{array}$ & 6 & 3 & 8 & \multirow{4}{*}{$\begin{array}{l}\text { Dano à saúde } \\
\text { do consumidor } \\
\text { e à imagem da } \\
\text { empresa }\end{array}$} & 144 & Colocação de placas de aviso \\
\hline & $\begin{array}{l}\text { Falta de } \\
\text { alimentação }\end{array}$ & 4 & 2 & 10 & & 80 & $\begin{array}{l}\text { Contração de responsável ou } \\
\text { orientação do atual }\end{array}$ \\
\hline & $\begin{array}{l}\text { Falta de } \\
\text { Vacinação }\end{array}$ & 6 & 9 & 9 & & 486 & Maior controle do lote de vacinas \\
\hline & $\begin{array}{l}\text { Seleção } \\
\text { inadequada das } \\
\text { matrizes }\end{array}$ & 6 & 7 & 9 & & 378 & Seleção mais criteriosa dos avozeiros \\
\hline \multirow{4}{*}{$\begin{array}{l}\text { Morte de } \\
\text { Frango }\end{array}$} & $\begin{array}{l}\text { Falta de } \\
\text { alimentação }\end{array}$ & 4 & 2 & 10 & \multirow{4}{*}{$\begin{array}{l}\text { Perdas } \\
\text { financeiras e } \\
\text { dificuldade no } \\
\text { planejamento }\end{array}$} & 80 & $\begin{array}{l}\text { Contratação de responsável ou } \\
\text { orientação do atual }\end{array}$ \\
\hline & $\begin{array}{l}\text { Doenças em } \\
\text { geral }\end{array}$ & 4 & 6 & 10 & & 240 & Contratação de veterinário \\
\hline & Falta de água & 5 & 2 & 8 & & 80 & $\begin{array}{l}\text { Manutenção da rede de } \\
\text { abastecimento }\end{array}$ \\
\hline & $\begin{array}{l}\text { Excesso na } \\
\text { capacidade }\end{array}$ & 6 & 7 & 8 & & 336 & Contagem mais rigorosa do lote \\
\hline \multirow{4}{*}{$\begin{array}{l}\text { Frango } \\
\text { abaixo do } \\
\text { peso }\end{array}$} & $\begin{array}{l}\text { Falta de } \\
\text { alimentação }\end{array}$ & 4 & 2 & 10 & \multirow{4}{*}{$\begin{array}{l}\text { Perdas } \\
\text { financeira } \\
\text { devido à falta } \\
\text { de matéria- } \\
\text { prima para } \\
\text { produção de } \\
\text { processados }\end{array}$} & 80 & $\begin{array}{l}\text { Contratação de responsável ou } \\
\text { orientação do atual }\end{array}$ \\
\hline & Doenças & 5 & 6 & 10 & & 300 & Contratação de veterinário \\
\hline & $\begin{array}{l}\text { Falta de } \\
\text { vitaminas }\end{array}$ & 2 & 8 & 10 & & 160 & Contratação de zootecnista \\
\hline & Falta de espaço & 6 & 7 & 8 & & 336 & Contagem mais rigorosa do lote \\
\hline \multirow{4}{*}{$\begin{array}{l}\text { Pintinho } \\
\text { com aspecto } \\
\text { ruim }\end{array}$} & $\begin{array}{l}\text { Brigas entre } \\
\text { pintinhos }\end{array}$ & 7 & 5 & 2 & \multirow{4}{*}{$\begin{array}{l}\text { O frango não } \\
\text { alcança o peso } \\
\text { adequado }\end{array}$} & 70 & Ambiente mais calmo \\
\hline & $\begin{array}{l}\text { Falta de } \\
\text { alimentação } \\
\text { adequada }\end{array}$ & 4 & 2 & 10 & & 80 & $\begin{array}{l}\text { Contratação de responsável ou } \\
\text { orientação do atual }\end{array}$ \\
\hline & Doenças & 5 & 6 & 10 & & 300 & Contratação de veterinário \\
\hline & $\begin{array}{l}\text { Pintinhos sujos } \\
\text { (melados) }\end{array}$ & 7 & 6 & 5 & & 210 & Aquecimento adequado \\
\hline \multirow{6}{*}{$\begin{array}{l}\text { Limpeza } \\
\text { inadequada }\end{array}$} & $\begin{array}{l}\text { Dedetização } \\
\text { incorreta }\end{array}$ & 3 & 5 & 10 & \multirow{6}{*}{$\begin{array}{l}\text { Possível } \\
\text { propagação de } \\
\text { doenças }\end{array}$} & 150 & $\begin{array}{l}\text { Contratação de uma empresa } \\
\text { terceirizada responsável }\end{array}$ \\
\hline & $\begin{array}{l}\text { Poucos dias de } \\
\text { repouso do } \\
\text { galpão }\end{array}$ & 9 & 6 & 10 & & 540 & $\begin{array}{l}\text { Maior intervalo para que o galpão } \\
\text { possa ficar de repouso }\end{array}$ \\
\hline & $\begin{array}{l}\text { O piso não foi } \\
\text { retirado }\end{array}$ & 2 & 10 & 10 & & 200 & $\begin{array}{l}\text { Contratação de um maior número de } \\
\text { pessoas realizar a retirada }\end{array}$ \\
\hline & $\begin{array}{l}\text { Bebedouros e } \\
\text { comedouros não } \\
\text { foram limpos } \\
\text { corretamente }\end{array}$ & 8 & 8 & 9 & & 576 & $\begin{array}{l}\text { Maior tempo para o avicultor } \\
\text { realizar suas tarefas }\end{array}$ \\
\hline & $\begin{array}{l}\text { Ração totalmente } \\
\text { retirada do } \\
\text { galpão }\end{array}$ & 4 & 8 & 9 & & 288 & $\begin{array}{l}\text { Disposição de caminhões da empresa } \\
\text { integrada para realizar essa tarefa }\end{array}$ \\
\hline & $\begin{array}{l}\text { Falta de limpeza } \\
\text { nas caixas } \\
\text { d'água e silo }\end{array}$ & 5 & 7 & 9 & & 315 & $\begin{array}{l}\text { Maior tempo para o avicultor } \\
\text { realizar suas tarefas }\end{array}$ \\
\hline
\end{tabular}

Fonte: Resultados da pesquisa - Elaborada pelos autores

Como se pode observar, a Tabela 4 indica os principais perfis de falhas ocorridas no período compreendido entre a chegada do pintinho e a saída do frango para o abate. Na referida tabela, buscou-se descrever somente as causas dos perfis de falha que apontaram maior risco dentro de cada um, excluindo-se, portanto, 
aquelas cujo risco foi considerado muito pequeno e de baixa interferência no planejamento da empresa rural.

Os resultados obtidos permitem ver que os erros com maior índice de risco (NPR) foram aqueles associados à etapa de limpeza do galpão. Segundo se observou, isso se deve ao fato de as falhas nessa etapa serrem de difícil detecção pela baixa tecnologia disponível nas granjas e pela alta severidade desses erros. Deve-se lembrar que um problema nessa etapa pode contaminar todo o plantel e, além de acarretar prejuízos financeiros ao produtor, pode contaminar o frango e levar possíveis doenças ao consumidor final.

Os problemas com maior índice de risco foram: bebedouros e comedouros, que não foram limpos corretamente, e poucos dias de descanso do galpão. Esses problemas devem ser analisados com maior cuidado porque, apesar de vinculados a atividades simples, podem ocasionar danos graves ao plantel e também gerar, de forma secundária, outras falhas apontadas nesse estudo. Outros itens graves, como falta de vacinação e falta de oferta de vitaminas, também são muito importantes, porém de menor risco, em virtude da baixa ocorrência.

Em muitos casos, as ações necessárias para evitar falhas são recorrentes, como contratação de veterinário e de profissional especializado. Tal procedimento contribui sobremaneira para a diminuição de um maior número de falhas. Nesse sentido, percebe-se que ações como tais devem constar no planejamento da empresa desde o início de suas atividades. Uma profissionalização maior das atividades rurais é cada vez mais necessária, entre outros pontos, pelo aumento da competição, em especial, com produtores de outros países.

A integração nesse sentido é de extrema importância por causa dos altos custos da contratação de profissionais especializados, o que deve ser englobado pela integradora e, em outros casos, pelas associações de produtores.

\section{CONSIDERAÇÕES FINAIS}

A aplicação do método FMEA mostrou que alguns erros no processo de criação de frango de corte são comuns e apresentam riscos muito altos. A limpeza do galpão é a etapa que deve ser feita de forma mais cuidadosa, pois as falhas que 
podem ocorrer nessa etapa trazem graves danos ao processo de criação do frango. As ações propostas para evitar essas falhas são de fácil implementação, porém necessitam de uma disponibilidade de recursos, fator nem sempre abundante para pequenos criadores de frango.

Para melhorar a qualidade do processo de criação de frango de corte, as empresas integradoras, as associações de produtores, sindicatos e o governo devem atuar diretamente com as granjas de modo a oferecer treinamento e disponibilizar recursos e profissionais especializados, garantindo uma melhor qualidade do frango de corte brasileiro.

Percebe-se ainda que um apontamento das falhas e, por conseguinte, uma maior preocupação dos produtores em relação aos possíveis erros, facilita o planejamento como um todo, haja vista que entre os diversos erros factíveis de serem evitados pela prática de gestão da qualidade encontram-se, no caso das granjas de frango de corte, desde a falta da matéria-prima até falhas mais graves como a contaminação.

Entre outros aspectos importantes verificados por meio desse estudo estão as ações de pequeno impacto financeiro para o pequeno empresário rural, entre elas a necessidade de um maior tempo para a realização das tarefas e poupar a cadeia como um todo de grandes danos que vão desde sua imagem frente aos consumidores até multas e indenizações por problemas diversos.

O método FMEA contribui, entre outros pontos, para a resolução dos chamados problemas estruturados, pois, por meio da implementação do método passa-se a conhecer melhor os possíveis erros e falhas que possam vir a ocasionar esses problemas, dando ao gestor segurança no tratamento dessas questões.

No que tange ao processo de criação de frangos, a aplicação do método FMEA permite, pelo cálculo do número de prioridades do risco, uma hierarquização das falhas, possibilitando um direcionando de recursos para a adoção de ações que tenham como objetivo a diminuição dessas falhas e a minimização de erros no processo de criação de frango de corte. Pela adoção dessas ações, torna-se factível tanto para a integradora, quanto para o integrado, a realização de um planejamento com um horizonte mais amplo, haja vista que o conhecimento das falhas e a adoção das ações para evitá-las diminuem o risco de intempéries no 
processo de criação, o que poderia impactar os demais elos da cadeia, levando a perdas a todos os seus agentes. Entre as principais dificuldades na aplicação do método, está a falta de familiaridade dos envolvidos na sua implantação com rotinas simples, como, por exemplo, o preenchimento de formulários; por outro lado, percebe-se que a grande experiência no que toca à criação de frangos possibilita uma identificação mais rápida e eficiente das falhas e das suas causas.

Percebe-se que a aplicação desse método contribui para a realização do planejamento interno da granja, levando-se em conta Chiavenato (2003), que aponta ter o planejamento o objetivo de maximizar os resultados e minimizar as deficiências da empresa, haja vista que o este planejamento aponta as principais deficiências no processo de criação dos frangos (atividade única da empresa), contribuindo para sua minimização, diminuindo, entre outros aspectos, a perda de produto e o retrabalho em algumas ações, contribuindo, assim, para a maximização do lucro.

\section{REFERÊNCIAS}

AUTOMOTIVE INDUSTRY ACTION GROUP (AIAG). Potential failure mode and effects analysis (fmea) reference manual. 2ed., Southfield, MI, AIAG, February.1995

ARAÚJO, L.F et al. Diferentes critérios de formulação de rações para frangos de corte no período de 1 a 21 dias de idade. Rev. Bras. Cienc. Avic. Campinas, v.4, n.3, Sept./Dec. 2002.

ASSOCIAÇÃO BRASILEIRA DOS PRODUTORES E EXPORTADORES DE FRANGO, 2009. Disponível em:

$<$ http://www.abef.com.br/noticias portal/exibenoticia.php?notcodigo=2389 $>$. Acesso em: 02 abr. 2011

BROH, R.A. Managing quality for higher profits. New York: Mc Graw Hill, 1974.

CHIAVENATO, I. A. S.; Planejamento estratégico, fundamentos e Aplicações 4 ed. Rio de Janeiro: Elsevier, 2003.

CROSBY, P. B. The eternally successful organization. New York: McGraw-Hill, 1988

Zero defects. [S.L.]: Quality Progress, 1992.

Quality is free. New York: New American Library, 1979.

Revista Produção Online. Florianópolis, SC, v.11, n. 3, p. 757-778, jul./set., 2011. 
CONFEDERAÇÃO DA AGRICULTURA E PECUÁRIA DO BRASIL, 2008. Disponível em: <www.cna.org.br/site/down anexo.php?q=E22 19765VBPMAl2008.pdf >.

Acesso em: 15 jun. 2010.

CONTI, E.A.; CAMPANI, D.B.; FMEA como ferramenta de apoio à implementação do sistema de gestão ambiental.2007. Disponível em:

$<$ http://www. saneamento.poli.ufrj.br/documentos/24CBES/VI-122.pdf > . Acesso em: 18 jun. 2010

DAVIS, J. H.; GOLDEBERG, R. A Concept of agribusiness. Boston: Havard University, 1957.

DEMING, W.E.; Out of the crisis: quality, productivity and competitive position. Cambridge: Cambridge University Press. 1982

OLIVEIRA, D. P. R.; Planejamento estratégico: conceitos, metodologias e práticas. 20 ed. São Paulo: Atlas, 2004.

FEIGENBAUM,A.V.; Total quality control. New York: Mcgraw-hill, 1986.

GARVIN, D.A.; Managing quality: the strategic and competitive edge. Nova York: Harvard Business School, 1988

ISCARPELLI, M.; Planejamento e controle da produção. In: BATALHA, M.O. (coord) et al. Gestão Agroindustrial. São Paulo: Atlas, 2007. 336-429 p.

ISHIKAWA, K. What Is total quality control? the japanese way. New York: Prentice-Hall, 1985.

IVEY, F.J. Desenvolvimento e aplicação de modelos de crescimento para frangos de corte. In: SIMPÓSIO INTERNACIONAL ACAV DA EMBRAPA SOBRE NUTRIÇÃO DE AVES, 1, 1999. Anais... 1999. v.1 p.22-36,

JURAN, J. M. Planejando para a qualidade. São Paulo: Pioneira, 1990.

MARTINS, F. M.; TALAMINI, D. J. D.; NOVAES, M. Avicultura: situação e perspectivas brasileira e mundial. 2006. Disponível em:

$<$ http://www.cnpsa.embrapa.br/down.php?tipo=artigos\&cod artigo=194 $>$. Acesso em: 14 jun. 2010

MCDERMOTT,R.E.; MIKULAK, R.J.; BEAUREGARD, M.R.; the basics of FMEA. P.O.BOX: Productivity. 1996

MOREIRA, J. et al Efeito da densidade populacional sobre desempenho, rendimento de carcaça e qualidade da carne em frangos de corte de diferentes linhagens comerciais. R. Bras. Zootec., v.33, n.6, p.1506-1519, 2000. 
MORETTI, D. de C.; BIGATTO, B. V. Aplicação do FMEA: estudo de caso em uma empresa do setor de transporte de cargas. Disponível em:

<http://www.nortegubisian.com.br/\%20artigos/fmea.pdf >. Acesso em: 13 maio 2010

MOURA, C. Análise de modos e efeitos de falha potencial (FMEA): manual de referência. SAE J-1739, 2000.

OOKALKAR, A.D; JOSHI.A.G.; OOKALKAR,D.S. Quality improvement in haemodialysis process using FMEA.: International Journal of Quality \& Reliability Management, v. 26, n. 8, p. 817-830, 2009.

OLISZESKI, C.A.N.; COLMENERO,J.C.;Definição de parâmetros para a construção de modelos de planejamento agrícola: um cenário para otimização de processos agroindustriais. Revista Gestão Industrial. v. 6, n. 02: p. 45-68, 2010

PADILHA, A.C.M. et al.; O desenvolvimento do diagnóstico estratégico em propriedades rurais do agronegócio: análise ambiental em uma propriedade rural familiar.(2010) Disponível em:<http://www.ingepro.com.br/index.php/ingepro/article/view/254/212> Acesso em 13 jun. 2010

PFEIFER, T. Qualitätsmangement strategien, methoden, techniken. München: C. Hanser Verlag, 1994.

RICHETTI, A.; SANTOS, A.C. dos. O sistema integrado de produção de frango de corte em Minas Gerais: uma análise sob a ótica da ECT. Disponivel em: <https://ageconsearch.umn.edu/bitstream/43354/2/revista_v2_n2_juldez_2000_3.pdf>. Acesso em: 10 maio 2010.

ROONEY, J.J., KILKELLY, J. No menu de hoje: qualidade. Revista Banas, p. 10-20, ago. 2002.

SAE. Potential failure mode and effects analysis in design (design FMEA) and potential failure mode and effects analysis in manufacturing and assembly processes (process FMEA) and effects analysis for machinery (machinery FMEA).Warrendale, PA: SAE, 2002.

SILVA JR, A.G.; Gestão ambiental e da qualidade ambiental no agronegócio. Viçosa: UFV. 2003. 104 p.

SOLOMON, D. V. Como fazer uma monografia. 11. ed. São Paulo: Martins Fontes. 2004.

STAMATIS, D.H., Failure mode and effect analysis: FMEA from Theory to Execution. Milwaukee/Wisconsin: American Society for Quality (ASQ), 1995. 
STRINGHINI, J.H. et al. Efeito do peso inicial dos pintos e do período da dieta préinicial sobre o desempenho de frangos de corte. R. Bras. Zootec., v.32, n.2, p.353360, 2003.

TENG, S.G. et al. Implementing FMEA in a collaborative supply chain environment. International Journal of Quality \& Reliability Management, v. 23, n. 2, p. 179-196, 2006.

TOLEDO, J.C.; AMARAL, D.C. FMEA: análise dos tipos e efeitos de falha. 2000. Disponível em: <http://www.gepeq.dep.ufscar.br/arquivos/FMEA-APOSTILA.pdf>. Acesso em: 17 maio 2010.

VILCKAS, M. Determinantes da tomada de decisão sobre as atividades produtivas rurais: proposta de um modelo para a produção familiar. 2004. 143f. Dissertação (Mestrado em Engenharia de Produção) - Universidade Federal de São Carlos, São Carlos.

Vieira, M.M.F. A comparative study on quality management in the Brazilian and the Scotish prison service. 1996. 234p. Thesis (Ph.D.)- Department of Business Studies, university of Edinburgh, Scotland, UK, 1996.

Vieira, M.M.F. e Carvalho, C.A.P. Qualidade e objetivos: implicações teóricas e metodológicas para a análise das organizações. In: VIEIRA, M.M.F. E OLIVEIRA, L.M.B. Administração contemporânea: perspectivas estratégicas. São Paulo: Atlas, 1999.

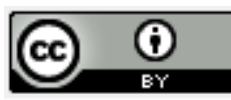

Artigo recebido em 21/08/2010 e aceito para publicação em 11/06/2011. 